\title{
Análise Comparativa do Desempenho de Empresas do Setor de Materiais Básicos listadas na BM\&FBovespa que apresentam Responsabilidade Social
}

\author{
Comparative Analysis of Companies Performance Sector Basic Materials listed \\ on BM\&FBovespa presenting Social Responsibility \\ Moacir Manoel Rodrigues Junior \\ moacir_ro@hotmail.com \\ FURB
}

\author{
Lara Fabiana Dallabona \\ larafdallabona@hotmail.com
}

FURB

\author{
Carlos Eduardo Facin Lavarda \\ clavarda@furb.br
}

FURB

\begin{abstract}
Resumo
O estudo objetiva avaliar comparativamente o desempenho das empresas pertencentes ao setor de materiais básicos da BM\&FBOVESPA que apresentam responsabilidade social com empresas que não apresentam esta característica. Para tanto, foi desenvolvida uma pesquisa descritiva, conduzida por meio de estudo documental com aplicação da Análise Envoltória de Dados (DEA). Os resultados demonstram que empresas que possuam responsabilidade social neste setor tendem a ter um desempenho inferior as empresas sem esta característica. Concluise que o setor não apresenta linearidade na distribuição da eficiência e identifica-se um grupo com alta eficiência e outro com baixa eficiência.
\end{abstract}

Palavras-chave: Avaliação de Desempenho. Responsabilidade Social. Ética. Gestão Ambiental. DEA.

\begin{abstract}
The study aims to comparatively evaluate the performance of the companies belonging to the basic materials sector of BM\&FBOVESPA which have social responsibility with companies that do not have this feature. To that end, we developed a descriptive study, conducted through documental study with application of data envelopment analysis (DEA). The results show that companies that have social responsibility in this sector tend to underperform companies without this feature. It follows that the sector does not have the linearity in the distribution efficiency and identifies a group with high efficiency and one with low efficiency. Keywords: Performance Assessment. Social Responsibility. Ethics. Environmental Management. DEA.
\end{abstract}

Artigo recebido em: 20.05.2012; Aceito em: 13.12.2012

\section{INTRODUÇÃO}

A responsabilidade social corporativa é "a decisão voluntária de comprometimento da gestão das organizações que passam a contribuir, mesmo não estando ligadas ao objeto social da empresa, em atividades para uma sociedade mais justa e para um ambiente mais limpo" (CARDOSO, OLIVEIRA e HOLANDA, 2010, p. 3). Neste contexto, é relevante destacar que as empresas socialmente responsáveis, não atribuem o sucesso gerencial apenas aos administradores e sócios proprietários, mas também aos interesses dos trabalhadores, 
fornecedores, clientes, concorrentes e a sociedade de maneira geral (CARDOSO; OLIVEIRA; HOLANDA, 2010).

A responsabilidade social é uma forte aliada para continuidade, desenvolvimento e crescimento das organizações. Neste sentido "cresce a conscientização, por parte da sociedade, do papel imprescindível que as grandes organizações têm diante das questões sociais, assim como a cobrança por uma atuação responsável e uma postura que explicite a preocupação com tais questões.” (DUARTE; TORRES, 2005, p. 27).

Além da responsabilidade social, é relevante destacar o papel da ética social, envolvendo questões relacionadas às atividades operacionais diárias das organizações, haja vista que o papel ético empresarial não é apenas o conhecimento da ética em si, mas em sua aplicação prática. É neste sentido que Duarte e Torres (2005, p. 30) citam que "ser ético não significa conduzir-se eticamente quando for conveniente, mas fazê-lo o tempo todo e com todos os stakeholders com os quais a empresa se relaciona".

Para que a empresa faça jus ao papel ético social desempenhado, há a necessidade de possuir uma gestão ambiental altamente confiável, preservando o meio ambiente em que atuam. Para Tachizawa (2002, p. 24-25) a gestão ambiental "é a resposta natural das empresas ao novo cliente, o consumidor verde e ecologicamente correto. A empresa verde é sinônimo de bons negócios e no futuro será a única forma de empreender negócios de forma duradoura e lucrativa." $\mathrm{O}$ autor argumenta ainda que "o quanto antes as organizações começarem a enxergar o meio ambiente como seu principal desafio e como oportunidade competitiva, maior será a chance de que sobrevivam."

Diante do contexto ambiental dos quais as organizações estão expostas é relevante destacar que ambas precisam avaliar constantemente seu desempenho para que possam tomar medidas corretivas, caso constate-se quaisquer irregularidades. É por este motivo que Pereira, (1999, p. 188) cita que "[...] o exercício da análise e do julgamento sobre qualquer situação que exija uma apreciação de fatos, idéias, objetivos e, também, uma tomada de decisão a fim de se atingir uma situação desejada" é considerada um ato de avaliação de desempenho.

Sendo assim, o processo de avaliação de desempenho passa a ser uma forma de se tomar decisões consideradas adequadas, constituindo, neste caso, "um processo complexo que incorpora, além das características informativas necessárias para se julgar adequadamente um desempenho, requisitos essenciais para se integrar ao processo de gestão, em suas fases de planejamento, execução e controle" (PEREIRA, 1999, p. 189).

Tendo em vista a contextualização descrita sobre responsabilidade social, ética, gestão ambiental, e avaliação de desempenho das organizações, apresentam-se a pergunta de pesquisa que norteia este estudo: Qual o desempenho das empresas do setor de materiais básicos da BM\&FBovespa que apresentam responsabilidade social quando comparadas com empresas que não apresentam esta característica? Tem-se, portanto que o objetivo do estudo é avaliar comparativamente o desempenho das empresas pertencentes ao setor de materiais básicos da BM\&FBovespa que apresentam responsabilidade social com empresas que não apresentam esta característica.

Justifica-se a elaboração deste estudo, por considerar relevantes os aspectos relacionados ao meio ambiente, gestão ambiental, responsabilidade social, ética e principalmente, por analisar o desempenho de empresas que apresentam responsabilidade social em suas atividades operacionais. As pressões exercidas pela sociedade em relação às empresas que não respeitam o meio ambiente, vem, aumentando gradativamente, haja vista que "por esta razão, aliada a exigência do mercado, estas empresas estão sendo obrigadas a adotar uma política de controle, preservação e recuperação ambiental a fim de garantir sua continuidade." (SANTOS et al. 2001, p. 90). Neste caso é que "o mercado de capitais também captou prontamente esta tendência e passou a levar crescentemente em consideração o aspecto ambiental em suas 
decisões de investimentos", tornando relevante o desenvolvimento de pesquisas que envolvem esta temática ambiental (DONAIRE, 1994, p. 70).

Espera-se que este estudo contribua para discussões relacionadas ao meio ambiente, envolvendo aspectos voltados à responsabilidade social, ética organizacional e gestão ambiental sustentável. Neste contexto, o processo de avaliação de desempenho das organizações que vierem a apresentar responsabilidade social, é relevante, haja vista que "a responsabilidade social diz respeito à conduta que as organizações têm no relacionamento com os seus públicos e/ou stakeholders e ao seu comportamento diante das demandas e necessidades de todos os que são afetados direta ou indiretamente por elas" (SANTOS, 2005, p. 111).

Visando, portanto, alcançar o objetivo proposto, realizou-se uma pesquisa descritiva, conduzida por meio de um levantamento documental nos relatórios financeiros das empresas listadas no setor de atuação de materiais básicos da BM\&FBovespa. Utilizou-se como método estatístico para analise do desempenho das empresas, a Análise Envoltória de Dados (DEA), do qual busca avaliar a eficiência das empresas.

A estrutura do estudo contempla seis seções, considerando esta de cunho introdutório, que apresenta uma contextualização geral do tema, pergunta de pesquisa, objetivo e justificativa. Após aborda aspectos conceituais sobre responsabilidade social, ética e gestão ambiental seguido do tópico que trata da avaliação de desempenho. A próxima seção tem como objetivo apresentar os aspectos metodológicos que norteiam esta pesquisa. A quinta seção apresenta a descrição e análise dos dados, e por fim, as considerações finais do estudo, respondendo a questão de pesquisa.

\section{RESPONSABILIDADE SOCIAL, ÉTICA E GESTÃO AMBIENTAL}

As mudanças nas organizações ocorrem por meio das implementações de ações voltadas aos seus empregados, processos, escolha da matéria-prima, seleção de fornecedores e atuação em seu ambiente por meio da participação em programas junto à comunidade onde a empresa está inserida (SALAMONI; GALLON; MACHADO, 2007). Neste contexto, é relevante destacar que a responsabilidade social pode ser definida como "[...] o compromisso que uma organização deve ter para com a sociedade, expresso por meio de atos e atitudes que a afetam positivamente, de modo amplo, ou a alguma comunidade, de modo específico, agindo proativamente e coerentemente no que tange a seu papel específico na sociedade e a sua prestação de contas para com ela" (ASHLEY, 2003, p, 6).

Donaire (1999, p. 200) define que a responsabilidade social "implica um sentido de obrigação para com a sociedade. Esta responsabilidade assume diversas formas, entre as quais se incluem proteção ambiental, projetos filantrópicos e educacionais, planejamento da comunidade, equidade nas oportunidades de emprego, serviços sociais em geral, de conformidade com o interesse público." Para Duarte e Torres (2005, p. 42) "a responsabilidade social nas empresas caminha cada vez mais para um olhar estratégico, que deve estar incorporado à gestão da organização: seus valores, missão, visão e processos."

No contexto da responsabilidade ética das organizações, Ashley (2003, p. 50) cita que "responsabilidade éticas correspondem a atividades, práticas, políticas e comportamentos esperados (no sentido positivo) ou proibidos (no sentido negativo) por membros da sociedade, apesar de não codificados em leis." Seguindo o mesmo raciocínio, o autor cita que a responsabilidade ética envolve certos valores morais, mencionando que "em outras palavras, os valores morais de um grupo ou organização definem o que é ser ético para si e, a partir daí, elaboram-se rígidos códigos éticos que precisam ser seguidos sob pena de ferirem os valores morais preestabelecidos". 
Para Duarte e Torres (2005, p. 24) a responsabilidade social vem surgindo como um resgate das funções sociais exercidas pela empresa, tendo como objetivo "promover o desenvolvimento humano sustentável, que atualmente transcende o aspecto ambiental e se estende por outras áreas (social, cultural, econômica, política) [...]”. As autoras mencionam ainda que as empresas procuram "[...] superar a distância entre o social e o econômico, obrigando as empresas a repensar seu papel e a forma de conduzir seus negócios".

Relacionando a responsabilidade social com a ética das organizações, concorda-se com Santos, (2005, p. 119) quando cita que "a responsabilidade social e a ética estão intrinsecamente ligadas. A ética é a base da responsabilidade social e se expressa por meio dos princípios e valores adotados pela organização para a condução dos negócios.”. A Autora descreve ainda que "[...] a responsabilidade social é a postura das empresas no dia-a-dia, visível no comportamento que as empresas têm ao lidar com as questões e demandas dos seus públicos e da sociedade"

Já Duarte e Torres (2005, p. 28) argumentam que as organizações são compreendidas como tendo um papel de destaque na sociedade, no que tange à renovação social, devendo portanto, todos os envolvidos para com as atividades operacionais da empresa, "buscar apreender a ética em suas ações e processos para que possam sobreviver, desenvolver-se, superar-se, evitando os erros anteriores e propondo constantemente novos caminhos para o alcance de suas metas."

Tachizawa (2002, p. 24) relata que "a gestão ambiental e a responsabilidade social, enfim, tornam-se importantes instrumentos gerenciais para capacitação e criação de condições de competitividade para as organizações, qualquer que seja seu segmento econômico." As empresas socialmente responsáveis devem seguir alguns estágios envolvendo desde a fase inicial até a fase mais avançada, conforme argumenta a Fundação para o Prêmio Nacional da Qualidade (2001), sendo: 1) a empresa não assume nenhum tipo de responsabilidade perante o meio social; 2) as empresas reconhecem os impactos ambientais causados pelas suas atividades operacionais, buscando promover o comportamento ético perante a sociedade; 3) as empresas iniciam processos de reconhecimento dos impactos de seus produtos, processos internos e instalações de equipamentos exercendo liderança nas questões que envolvem a sociedade; 4) os processos de reconhecimento da fase anterior passam para o processo de sistematização, exercendo a organização, o papel de liderança nas questões de interesse da comunidade em geral; 5) todo o processo de avaliação dos impactos causados pela empresa, por meio dos seus produtos, processos e instalações está finalmente sistematizado, vindo a buscar as principais questões públicas. Este estágio deve ser considerado pela organização, como o mais avançado, devendo ser considerado pela organização como meta, buscando atingir determinado objetivo imposto pela empresa (TACHIZAWA, 2002).

$\mathrm{Na}$ visão de Salamoni, Gallon e Machado (2007, p, 25) "o reconhecimento de que o meio ambiente necessitava de cuidados, fez com que as empresas de grande porte começassem, nos anos 80, a analisar os investimentos ambientais como uma vantagem competitiva perante os consumidores, e não como custo." Neste sentido, Franco (2000, p. 36) menciona que "o Planejamento Ambiental pressupõe três princípios de ação humana: os princípios da preservação, da recuperação e da conservação do meio ambiente." A autora (p. 37) cita ainda que "o Planejamento Ambiental é portanto também um Planejamento Territorial Estratégico, Econômico-ecológico, Sociocultural, Agrícola e Paisagístico.” É por motivos relacionados a busca da excelência ambiental, que Elkington e Burke (1989, apud DONAIRE, 1999, p. 5051) citam alguns passos a serem seguidos para atingir tal excelência, sendo eles:

1. Desenvolva e publique uma política ambiental.

2. Estabeleça metas e continue a avaliar os ganhos. 
3. Defina claramente as responsabilidades ambientais de cada uma das áreas e do pessoal administrativo (Linha ou Assessoria).

4. Divulgue interna e externamente a política, os objetivos e metas e as responsabilidades.

5. Obtenha recursos adequados.

6. Eduque e treine seu pessoal e informe os consumidores e a comunidade.

7. Acompanhe a situação ambiental da empresa e faça auditorias e relatórios.

8. Acompanhe a evolução da discussão sobre a questão ambiental.

9. Contribua para os programas ambientais da comunidade e invista em pesquisa e desenvolvimento aplicada à área ambiental.

10. Ajude a conciliar os diferentes interesses existentes entre todos os envolvidos: empresa, consumidores, comunidade, acionistas etc.

Ressalta-se que apesar das dificuldades de implantação de uma gestão ambiental que seja adequada por parte das empresas, os investimentos econômicos em inovações relacionadas ao meio ambiente podem vir a se tornar fontes significativas de vantagem competitiva no contexto do meio ambiente. (SALAMONI; GALLON; MACHADO, 2007, p. 26). Para Kinlaw (1997, p. 5) "a característica fundamental do desempenho sustentável é que ele sustenta o meio ambiente e sustenta a produção da empresa. Há hoje evidências suficientes para provar que o desempenho sustentável é uma meta factível e que muitas organizações estão bem encaminhadas na conquista dessa meta."

Donaire (1999) destaca que um processo ambiental amigável deve estar diretamente relacionado à poluição zero; nenhuma produção dos resíduos; nenhum tipo de risco para os funcionários; apresentar baixo consumo de energia; e usar eficientemente os recursos renováveis. Neste contexto, é necessário as empresas atentarem ao fato de que precisam impor metas para atingir a eficiência ambiental, pois não há conhecimento de como determinadas substancias podem acarretar prejuízos à longo prazo para o ambiente. Outra característica tem relação com os padrões estabelecidos, em que "muitas vezes por questões econômicas e políticas, podem estar muito aquém das reais necessidades sociais, provocando efeitos adversos ao meio ambiente que só serão avaliados no futuro." (DONAIRE, 1999, p. 54).

Para Melissa et al. (2010, p. 4) as deficiências causados no meio ambiente é, infelizmente, um fator relevante para a sociedade pois "fizeram com que a sociedade se voltasse para a Gestão Ambiental e o Desenvolvimento Sustentável como forma de garantir um convívio mais ameno e respeitoso com o meio ambiente e, principalmente, garantir sua continuidade." Quanto ao conceito de desenvolvimento sustentável, Franco (2000, p. 41) mencionou que "o desenvolvimento sustentável tem como finalidade a integração de preocupações ambientais ao bojo das políticas socioeconômicas, fazendo estas políticas responsáveis por seus impactos ambientais."

Bruno (2005, p. 162) declara que "a importância de adotar uma postura socialmente responsável cresce à medida que se torna evidente que uma sociedade cada vez mais fragilizada representa o risco para os próprios negócios das empresas." Para a autora, "ser socialmente responsável passa a ser mais do que apenas cumprir obrigações sociais e torna-se ponto estratégico para a organização, além de ser fator capaz de distingui-la das demais do mercado."

Para Bellen (2005) há cinco dimensões que envolvem a sustentabilidade ambiental das empresas, sendo a sustentabilidade na perspectiva econômica, perspectiva social, ambiental, geográfica e cultural. O Quadro 1 apresenta os principais conceitos das respectivas dimensões sustentáveis.

Quadro 1 - Dimensões da sustentabilidade ambiental

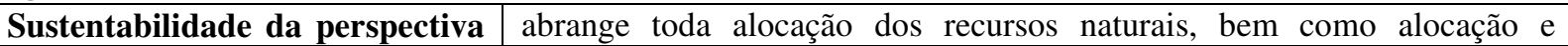




\begin{tabular}{|l|l|}
\hline econômica & $\begin{array}{l}\text { distribuição eficiente de tais recursos, sendo que para os economistas a } \\
\text { questão problema da sustentabilidade envolve a manutenção do capital em } \\
\text { todas as formas. }\end{array}$ \\
\hline $\begin{array}{l}\text { Sustentabilidade da perspectiva } \\
\text { Social }\end{array}$ & $\begin{array}{l}\text { está diretamente relacionada ao bem estar e convício social do ser } \\
\text { humano, envolvendo principalmente o bem estar e os meios utilizados } \\
\text { para aumentar a qualidade de vida da população. }\end{array}$ \\
\hline $\begin{array}{l}\text { Sustentabilidade da perspectiva } \\
\text { ambiental }\end{array}$ & $\begin{array}{l}\text { está intrinsecamente relacionada aos impactos causados pelas atividades } \\
\text { dos seres humanos para com o meio ambiente. O que deve ser feito para } \\
\text { reduzir impactos ambientais são a redução da utilização de combustíveis } \\
\text { fosseis, redução de substâncias poluentes, adotando praticas de } \\
\text { conservação, energia e recursos, aumentando assim a eficiência dos } \\
\text { recursos utilizados. }\end{array}$ \\
\hline $\begin{array}{l}\text { Sustentabilidade da perspectiva } \\
\text { geográfica }\end{array}$ & $\begin{array}{l}\text { a sustentabilidade geográfica pode ser alcançada por meio de uma melhor } \\
\text { distribuição dos assentamentos humanos e das atividades econômicas. } \\
\text { Deve-se procurar uma configuração rural-urbana mais adequada para } \\
\text { proteger a diversidade biológica, ao mesmo tempo em que se melhora a } \\
\text { qualidade de vida das pessoas. }\end{array}$ \\
\hline $\begin{array}{l}\text { Sustentabilidade da perspectiva } \\
\text { cultural }\end{array}$ & $\begin{array}{l}\text { é a dimensão da sustentabilidade mais difícil de ser concretizada, pois } \\
\text { relaciona todo o percurso da modernização não levando em conta o } \\
\text { rompimento da identidade cultural em um contexto espacial específico. }\end{array}$ \\
\hline
\end{tabular}

Fonte: adaptado de Bellen (2005).

Todas essas dimensões estão atreladas ao desenvolvimento sustentável das organizações, visando sempre, o melhor gerenciamento sustentável para que a empresa aufira bons resultados, reduzindo os impactos ambientais causados por suas atividades operacionais. Para Seiffert (2007, p. 48) a gestão ambiental "busca a condução harmoniosa dos processos dinâmicos e interativos que ocorrem entre os diversos componentes do ambiente natural e antrópico, determinados pelo padrão de desenvolvimento almejado pela sociedade." A autora destaca ainda que "gestão e gerenciamento ambiental têm, portanto, um caráter bem diferenciado à medida que o processo de gerenciamento está associado a medidas de caráter mais tático na organização, enquanto a gestão implica em processo de ordem mais estratégica." (SEIFFERT, 2007, p. 55).

\section{AVALIAÇÃO DE DESEMPENHO}

Alguns estudos desenvolvidos dedicaram atenção especial à avaliação de desempenho no contexto das empresas, abarcando diversos ramos do conhecimento científico, como economia, contabilidade, administração, psicologia, sociologia, entre outras, das quais estão preocupadas com a avaliação de desempenho das organizações. (KASSAI, 2002).

Conforme descreveu Kassai (2002, p. 35) mensurar o desempenho de uma empresa é uma questão considerada fértil para os estudos que envolvem diversas áreas do conhecimento. Cita a autora que "muito se tem escrito sobre indicadores de desempenho. Notas, percentuais, quocientes, montantes, multiplicadores, são muitas as formas numéricas utilizadas na aferição do desempenho." Dentre as principais características dos indicadores envolvidos na análise de desempenho, cita-se a objetividade, mensurabilidade, compreensibilidade, comparabilidade e custo.

Dentre as terminologias utilizadas para avaliação de desempenho, subentende-se que a avaliação pode ser considerada "[...] o exercício da análise e do julgamento sobre qualquer situações que exija uma apreciação de fatos, idéias, objetivos e, também, uma tomada de decisão a fim de se atingir uma situação desejada." (PEREIRA, 1999, p. 188). Este mesmo autor (p. 189) descreve ainda que mais especificamente, "o termo avaliação refere-se ao ato 
ou efeito de se atribuir valor, sendo que valor pode ser entendido num sentido qualitativo (mérito, importância) ou num sentido qualitativo (mensuração)."

No que tange a terminologia "desempenho", Pereira (1999, p. 193) menciona que é a operacionalização/realização de uma respectiva atividade ou conjunto de atividades inerentes ao processo da organização, afirmando que este conjunto de atividades "caracteriza o conceito de "desempenho" relativamente à empresa em sua totalidade. Esse desempenho resulta das várias atividades que são realizadas na empresa, interagindo no sentido de criarem as condições para sua sobrevivência e desenvolvimento."

Para que as empresas mantenham-se competitivas no mercado, há a necessidade de ambas utilizarem sistemas informativos que avaliem o seu desempenho, estando, portanto, condicionada a determinação de medidas de eficiência. (MACEDO et al. 2008). A definição para os indicadores de desempenho "faz parte de uma seqüência lógica de procedimentos para desenvolvimento e implementação de um sistema de mensuração e avaliação de desempenho." Neste caso, os autores discorrem ainda que determinar "quais as medidas que devem ser realizadas depende da complexidade do processo que se deseja avaliar, da sua importância em relação às metas estabelecidas pela empresa e da expectativa de uso gerencial posterior destes dados." (MACEDO, et al. 2008, p. 4).

Neste sentido, é relevante destacar que as atividades diárias das empresas estão atreladas às diversas dimensões operacionais. Pereira (1999, p. 193) apresenta uma Figura, representando "[...] as dimensões do desempenho na empresa, que simbolizam ângulos pelos quais ele pode ser observado, segundo algumas características próprias das atividades que o compõem (amplitude, natureza, ocorrência, tempo e qualidade)." A Figura 1 apresenta as respectivas dimensões na avaliação do desempenho das empresas, com suas respectivas características.

Conforme se observa na Figura 1, adaptada de Pereira (1999), as dimensões se interrelacionam. A dimensão que trata da amplitude relacionada às atividades da empresa envolve três conjuntos de informações, sendo informações globais, divisionais e funcionais. Dentro deste contexto, "todos os parâmetros (financeiros ou não financeiros) de avaliação de desempenho devem procurar promover a congruência entre os objetivos do "avaliado" e os da empresa em sua totalidade" (PEREIRA, 1999, p. 196). 


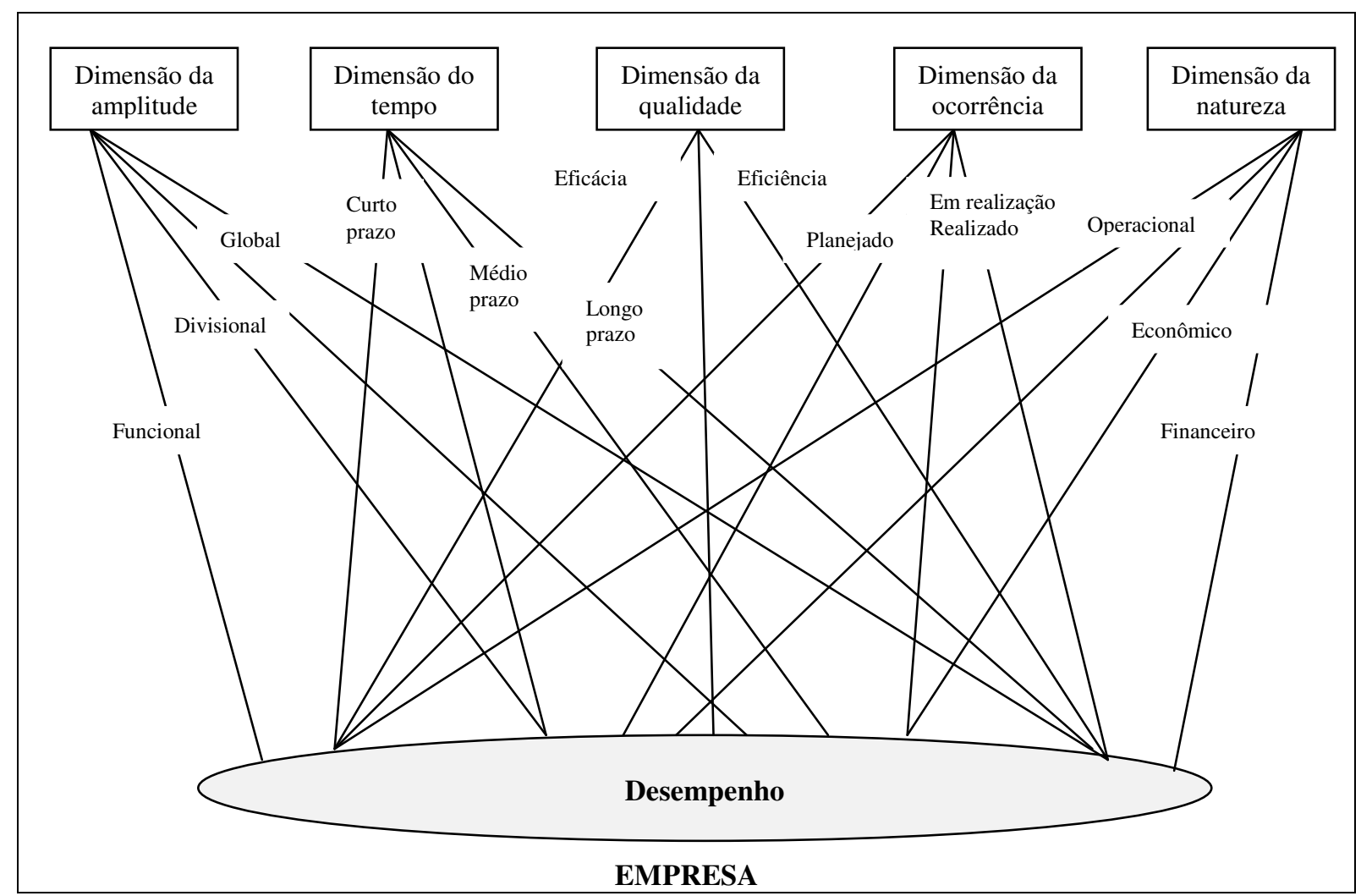

Figura 1 - Dimensões do desempenho na empresa.

Fonte: adaptado de Pereira (1999, p. 194).

A segunda dimensão esta relacionada ao tempo de atuação da empresa para com suas atividades operacionais. Neste sentido, Pereira (1999, p. 198-199) cita que "a dimensão temporal do desempenho pressupõe a continuidade do empreendimento e refere-se a um período que delimita uma atividade ou um conjunto delas. Pode relacionar-se ao desempenho futuro (planejado), presente (em realização) ou passado (realizado) das atividades." A dimensão que relaciona a qualidade com o ambiente empresarial e seu desempenho, envolve entre outros aspectos, a eficácia e a eficiência. Para o autor, "a eficácia em relação a uma atividade, refere-se à obtenção dos resultados desejados, enquanto a eficiência refere-se à relação recursos consumidos/produtos gerados."

A quarta dimensão, definida como dimensão de ocorrência esta relacionada com o desempenho auferido nas atividades operacionais das organizações, sendo que no planejamento define-se o que será executado, e no processo de execução, concretiza-se o planejado, ou seja, subdivide-se as atividades em desempenho planejado, que passará por realização e por fim será realizado (PEREIRA, 1999). Por último, porém não menos importante, tem-se a dimensão relacionada à natureza das atividades, envolvendo aspectos operacionais, econômicos e financeiros.

Quanto à avaliação de desempenho por meio dos aspectos operacionais, considera-se "o atingimento de determinados níveis (padrões) de eficiência, de utilização de equipamentos, de prazos, de segurança e de qualidade." Já o desempenho econômico "é caracterizado pelo aspecto econômico envolvido no desempenho operacional, próprio de toda atividade produtiva, e revela-se por seus resultados econômicos". Por fim, é importante destacar que o desempenho financeiro "refere-se aos prazos de pagamento e recebimento dos valores 
envolvidos nas atividades, bem como à captação e aplicação de recursos financeiros necessários" (PEREIRA, 1999, p. 197).

A análise de desempenho das empresas pode vir a ser conduzida determinando-se medidas de eficiência. Há quatro características relacionadas aos sistemas de análise e processo de avaliação do desempenho organizacional, sendo: "ter caráter relativo, utilizar variáveis financeiras, determinar funções de fronteira e trabalhar com a relação input-output.” É neste sentido que a Análise Envoltória dos Dados (DEA) “ [...] apresenta-se como uma medida de desempenho capaz de comparar a eficiência de várias unidades operacionais similares mediante a consideração explícita do uso de suas múltiplas entradas para a produção de múltiplas saídas.” (MACEDO et al. 2008, p, 5). Este estudo utilizar-se-á deste instrumento para avaliar comparativamente o desempenho das empresas pertencentes ao setor de materiais básicos da BM\&FBovespa que apresentam responsabilidade social com empresas que não apresentam esta característica.

\section{PROCEDIMENTOS METODOLÓGICOS}

O propósito deste artigo está em avaliar comparativamente o desempenho das empresas pertencentes ao setor de materiais básicos da BM\&FBovespa que apresentam responsabilidade social com empresas que não apresentam esta característica. Para que este objetivo seja atendido foram definidos os métodos e processos da pesquisa, que está definida, segundo as tipologias descritas por Raupp e Beuren (2008), como uma pesquisa descritiva quanto seus objetivos, bem como documental quanto aos procedimentos e quantitativa quanto sua abordagem.

Para Gil (1999) pesquisa descritiva é toda pesquisa cujo objetivo é descrever características de uma determinada amostra ou população. Esta abordagem evidencia a abordagem desta pesquisa, pois esta descreve o desempenho das empresas do setor de Materiais Básicos da BM\&FBovespa. A pesquisa documental por sua vez possui a característica de se utilizar de documentos como fonte de dados, informações e evidências. Também podem combinar dados publicados com outras formas de coleta (MARTINS e THEÓPHILO, 2009).

A pesquisa quantitativa, segundo Raupp e Beuren (2008), é a pesquisa que busca de instrumentos estatísticos para a coleta e análise dos dados. Esta abordagem não se preocupa em buscar o conhecimento da realidade dos fenômenos e sim descrever de forma geral o comportamento dos acontecimentos analisados.

Para analisar o desempenho das empresas observadas, foram coletados os dados de empresas que adotaram a condição de responsabilidade social. Esta característica é descrita pelo Índice de Sustentabilidade Empresarial - ISE divulgado pela BM\&FBovespa para empresas que adotam esta característica. Segundo Cardoso, Oliveira e Holanda (2010) o ISE é obtido por meio de um questionário minucioso realizado anualmente nas empresas que declaram possuir atividades Socioambientais.

O ISE do ano de 2009(BM\&FBovespa, 2009) descreve um total de 39 empresas. Dos setores definidos pela Bovespa, os três com maiores números de empresas são: setor de Utilidades Públicas com 13 empresas, Financeiro com nove empresas e o setor de Materiais Básicos com sete empresas. Para este estudo foi adotado o setor de Materiais Básicos, pois a atividade destas empresas está diretamente relacionada com o consumo de recursos naturais, haja vista, que a maior parte das empresas pertencentes a este setor é empresa de transformação.

Após definido o setor de atuação das empresas estudadas, foram coletados os demonstrativos contábeis no site da BM\&FBovespa. De um total de 49 empresas pertencentes ao setor analisado, 41 apresentaram seus balanços consolidados do ano de 2009, ano este utilizado para a análise. Dentre o conjunto de empresas coletadas estavam presentes empresas com e 
sem a característica de serem socioambientalmente sustentáveis. No Quadro 2 seguem descritas as empresas que participaram da amostra, e em destaque $(*)$ as empresas que estão listadas no ISE.

Para a análise do desempenho das empresas listadas no Quadro 2, foi utilizado o método de Data Envelopment Analysis -DEA (Análise Envoltória de Dados). Segundo Kassai (2002) o modelo DEA consiste em um problema de programação linear que busca relacionar na forma de um quociente produtos (outputs) com insumos (inputs), o objetivo do modelo está em determinar uma solução ótima em que é possível maximizar a quantidade de produtos minimizando a quantidade dos insumos.

Quadro 2 - Empresas que participaram da amostra

\begin{tabular}{|l|l||l|l|l|}
\hline 1 & DIXIE TOGA & 22 & ELEKEIROZ \\
\hline 2 & PETROPAR & 23 & GPC PART \\
\hline 3 & DURATEX* & 24 & M G POLIEST \\
\hline 4 & EUCATEX & 25 & PRONOR \\
\hline 5 & CELUL IRANI & 26 & UNIPAR \\
\hline 6 & MELHOR SP & 27 & MILLENNIUM \\
\hline 7 & FIBRIA* & 28 & QGN PARTIC \\
\hline 8 & KLABIN S/A & 29 & PARANAPANEMA \\
\hline 9 & SUZANO HOLD & 30 & CONFAB \\
\hline 10 & SUZANO PAPEL* & 31 & MANGELS INDL \\
\hline 11 & PROVIDENCIA & 32 & PANATLANTICA \\
\hline 12 & MAGNESITA AS & 33 & ALIPERTI \\
\hline 13 & SANSUY & 34 & TEKNO \\
\hline 14 & TRORION & 35 & ACOS VILL \\
\hline 15 & LITEL & 36 & FERBASA \\
\hline 16 & MMX MINER & 37 & SID NACIONAL \\
\hline 17 & VALE* & 38 & GERDAU* \\
\hline 18 & FER HERINGER & 39 & GERDAU MET* \\
\hline 19 & VALEFERT & 40 & USIMINAS \\
\hline 20 & YARA BRASIL & 41 & VICUNHA SID \\
\hline 21 & BRASKEM* & \\
\hline
\end{tabular}

Fonte: dados da pesquisa.

Segundo Vasconcellos, Canen e Lins (2006) "DEA define a eficiência de uma unidade em relação às melhores unidades de desempenho observadas". O método DEA é apresentado em dois modelos distintos, sendo que inicialmente o modelo desenvolvido por Charnes, Cooper e Rhode (1973) foi o modelo DEA CRS (Constants Return to Scale) posteriormente Banker, Charnes e Cooper (1984) desenvolveram o modelo DEA VRS (Variable Return to Scale). Para este estudo foi utilizado o Modelo CRS, que permite o estabelecimento de um ranking com os melhores desempenhos.

Kassai (2002) defendeu que os modelos DEA utilizados em estudos nacionais e internacionais de contabilidade, oferecem uma poderosa ferramenta de análise de desempenho. Afirma em seu estudo que os modelos DEA são uma ferramenta de benchmarking, pois analisam o desempenho da organização comparando com as melhores do conjunto de avaliação. 
Dentre os estudos referenciados pela autora supracitada, destaca-se Smith (1990), FernandezCastro e Smith (1994), Simak (1997 e 2000) que desenvolveram o modelo DEA utilizaram índices contábeis para a análise de desempenho. Os índices descritos por estes autores foram os utilizados neste estudo para a análise de eficiência de empresas do setor de Materiais Básicos da BM\&FBovespa. A Tabela 1 descreve a estatística descritiva das variáveis utilizadas para a elaboração do modelo de desempenho.

Tabela 1 - Estatística descritiva das variáveis analisadas

\begin{tabular}{c|l|c|c|c|c|c}
\hline & & Média & Mediana & $\begin{array}{c}\text { Desvio } \\
\text { Padrão }\end{array}$ & Máximo & Mínimo \\
\hline \multirow{5}{*}{ Inputs } & Vendas/AT & 0,9403 & 0,7569 & 0,8352 & 5,1736 & 0,1338 \\
\cline { 2 - 7 } & LL/AT & $-0,3838$ & 0,0405 & 2,6150 & 0,1742 & $-16,7067$ \\
\cline { 2 - 7 } & $\mathrm{CX} / \mathrm{AT}$ & 0,1166 & 0,0752 & 0,1285 & 0,6679 & 0,0004 \\
\cline { 2 - 7 } & (AC-PC)/AT & $-1,4843$ & 0,1574 & 10,8944 & 1,7536 & $-69,5082$ \\
\hline \multirow{3}{*}{ Outputs } & $\mathrm{AT}$ & 12525539 & 1466193 & 29288272 & 175739055 & 15869 \\
\cline { 2 - 7 } & $\mathrm{ELP}$ & 4757385 & 336829 & 10119783 & 56776226 & 1663 \\
\cline { 2 - 7 } & $\mathrm{PL}$ & 5074475 & 552333 & 15323209 & 95736974 & -1090528 \\
\hline
\end{tabular}

Fonte: dados da pesquisa

Conforme observa-se por meio da Tabela 1, os índices utilizados foram Vendas/Ativo Total (Output 1), Lucro Líquido / Ativo Total (Output 2), Caixa/Ativo Total (Output 3), (Ativo Circulante - Passivo Circulante)/Ativo Total (Output 4). Estes índices foram adotados como Outputs por descreverem o retorno da atividade das empresas. Como inputs foram adotados os índices Ativo Total (Input 1), Exigível Total (Input 2) e Patrimônio Líquido (Input 3). Estas variáveis são Inputs por caracterizarem o que a empresa emprega na execução de sua atividade. A próxima seção apresenta a descrição e análise dos dados referente a esta pesquisa.

\section{DESCRIÇÃO E ANÁLISE DOS DADOS}

A pesquisa utilizou dos dados contábeis financeiros das empresas do setor de Materiais Básicos para avaliar o desempenho destas empresas. Esta sessão se dispõe a descrever os resultados auferidos pelo processo de análise dos dados da pesquisa. O setor analisado, está dividido em subsetores pela BM\&FBovespa. Cada subsetor possui uma atividade diferente. Esta descrição está disposta na Tabela 2. 
Tabela 2 - Subsetores analisados

\begin{tabular}{l|c}
\hline Subsetor & No de empresas \\
\hline Embalagem & 2 \\
Madeira & 2 \\
Papel e Celulose & 6 \\
Materiais Diversos & 4 \\
Minerais metálicos & 3 \\
Fertilizantes e Defensivo & 3 \\
Petroquímicos & 6 \\
Químicos Diversos & 2 \\
Artefatos de Cobre & 1 \\
Artefatos de Ferro e Aço & 5 \\
Siderurgia & 7 \\
\hline Total & $\mathbf{4 1}$ \\
\hline
\end{tabular}

Fonte: dados da pesquisa.

A Tabela 2 apresenta que o subsetor com maior número de empresas analisadas é de Siderurgia com sete empresas, seguido pelos setores de Papel e Celulose e Petroquímicos com seis empresas cada.

$\mathrm{Na}$ sequência foram realizados os cálculos do modelo DEA CRS. Este modelo possibilitou descrever um ranking entre o desempenho de todas as empresas do setor analisado, em uma comparação entre as mesmas. Os resultados auferidos estão dispostos no Quadro 2 e nela encontram-se destacado as empresas que estão descritas no ISE.

A eficiência das empresas do Setor de Materiais Básicos, observada na Tabela 2, auferiu percentual de $100 \%$ para as empresas Celulose Irani, Sansuy, Trorion, MMX Miner, Pronor, QGN Participações e Tekno. Auferir 100\% de eficiência significa segundo Kassai (2002) dizer que a empresa é o ponto de referência para todo o setor de atuação. Desta forma é possível destacar que sete empresas analisadas são referência para este setor de atuação.

Na posição oposta do ranking de eficiência é possível descrever as empresas Gerdau, Gerdau Metalúrgica, Fibria e Litel como empresas ineficientes em comparação com as demais. Seus índices de eficiência estão abaixo de $1 \%$ e quatro destas empresas mais ineficientes, três estão no ISE. 
Quadro 2 - Grau de Eficiência das empresas analisadas.

\begin{tabular}{|c|c|c|c|c|c|}
\hline 1 & CELUL IRANI & $100,00 \%$ & 22 & DIXIE TOGA & $13,00 \%$ \\
\hline 2 & SANSUY & $100,00 \%$ & 23 & PARANAPANEMA & $10,36 \%$ \\
\hline 3 & TRORION & $100,00 \%$ & 24 & CONFAB & $9,78 \%$ \\
\hline 4 & MMX MINER & $100,00 \%$ & 25 & MILLENNIUM & $8,98 \%$ \\
\hline 5 & PRONOR & $100,00 \%$ & 26 & M G POLIEST & $7,92 \%$ \\
\hline 6 & QGN PARTIC & $100,00 \%$ & 27 & DURATEX (*) & $4,61 \%$ \\
\hline 7 & TEKNO & $100,00 \%$ & 28 & KLABIN S/A & $3,30 \%$ \\
\hline 8 & PANATLANTICA & $82,94 \%$ & 29 & SUZANO PAPEL (*) & $3,17 \%$ \\
\hline 9 & PETROPAR & $79,15 \%$ & 30 & SID NACIONAL & $3,06 \%$ \\
\hline 10 & MELHOR SP & $58,50 \%$ & 31 & VICUNHA SID & $2,92 \%$ \\
\hline 11 & ALIPERTI & $46,35 \%$ & 32 & YARA BRASIL & $2,25 \%$ \\
\hline 12 & EUCATEX & $44,34 \%$ & 33 & VALEFERT & $2,09 \%$ \\
\hline 13 & FERBASA & $41,52 \%$ & 34 & BRASKEM $(*)$ & $1,72 \%$ \\
\hline 14 & UNIPAR & $31,23 \%$ & 35 & USIMINAS & $1,65 \%$ \\
\hline 15 & MANGELS INDL & $25,46 \%$ & 36 & $\operatorname{VALE}(*)$ & $1,42 \%$ \\
\hline 16 & ACOS VILL & $23,42 \%$ & 37 & MAGNESITA SA & $1,41 \%$ \\
\hline 17 & FER HERINGER & $21,44 \%$ & 38 & LITEL & $0,88 \%$ \\
\hline 18 & PROVIDENCIA & $18,13 \%$ & 39 & GERDAU MET (*) & $0,41 \%$ \\
\hline 19 & SUZANO HOLD & $16,20 \%$ & 40 & FIBRIA (*) & $0,39 \%$ \\
\hline 20 & ELEKEIROZ & $15,46 \%$ & 41 & GERDAU $(*)$ & $0,38 \%$ \\
\hline 21 & GPC PART & $14,97 \%$ & & & \\
\hline
\end{tabular}

Fonte: dados da pesquisa.

A Tabela 3 apresenta o teste Mann-Whitney que testou a existência ou não de diferença estatisticamente significativa entre as médias das eficiências analisadas. Com um índice de significância de 0,4243, refutasse a hipótese e existência de diferença entre as médias. Contudo é possível observar que a média do grupo com Responsabilidade Socioambiental $(1,73 \%)$ e sem esta característica $(37,84 \%)$ possui grande diferença. A média geral do desempenho das empresas deste setor é de $32 \%$, de certa forma o desempenho das empresas que são responsáveis possui um desempenho inferior às demais empresas.

Tabela 3 - Teste de diferença de médias

\begin{tabular}{c|c|c}
\hline Grupo & Média da Eficiência & \multirow{2}{*}{ Sig. Mann-Whitney } \\
\hline C/RS & $1,73 \%$ & \multirow{2}{*}{0,4243} \\
\hline S/RS & $37,84 \%$ & \\
\hline Média Geral & $\mathbf{3 2 \%}$ & \\
\hline Fon
\end{tabular}

Fonte: dados da pesquisa.

Com base nos resultados expostos acima é possível afirmar que em empresas do setor de Materiais Básicos que possuem responsabilidade socioambiental possuem desempenho inferior as demais empresas, em sua maioria. Entretanto, o setor apresenta dois conjuntos definidos de empresas com maior eficiência com empresas com menor eficiência. 


\section{CONSIDERAÇÕES FINAIS}

Este estudo teve como objetivo avaliar comparativamente o desempenho das empresas pertencentes ao setor de materiais básicos da BM\&FBovespa que apresentam responsabilidade social com empresas que não apresentam esta característica. No âmago desta questão foram estabelecidos os métodos e procedimentos de análise para que este trabalho conseguisse responder aos objetivos. A análise consistiu no estudo dos índices contábeis das empresas do setor de Materiais Básicos da BM\&FBovespa, por meio do método de apoio a tomada de decisão da Análise Envoltória de Dados (DEA). Este método consiste em comparar cada empresa com a empresa com maior eficiência de seu grupo.

Retomando a questão problema desta pesquisa, que foi: Qual o desempenho das empresas do setor de materiais básicos da BM\&FBovespa que apresentam responsabilidade social quando comparadas com empresas que não apresentam esta característica? Em resposta a questão, pode-se descrever que o desempenho médio das empresas com responsabilidade social foi de $1,73 \%$ e das empresas sem esta característica foi de 37,84\%. Esta diferença não é estatisticamente significativa, conforme o teste de Mann-Whitney, entretanto a disparidade entre as médias é alta, o que leva a inferir que o desempenho das empresas com responsabilidade social foi inferior as empresas sem esta característica.

Uma constatação importante desta pesquisa foi que a eficiência das empresas do setor analisado, descreve uma polarização, com um conjunto de empresas com um índice de eficiência maior e outro grupo com empresas com um grau de eficiência inferior ao primeiro grupo. Dentro destes dois conjuntos, as empresas com responsabilidade social estão categorizadas como empresas com desempenho inferior as demais.

Desta forma destaca-se que o objetivo de avaliar o desempenho das empresas com responsabilidade social comparando com empresas sem responsabilidade social foi satisfeito, o que permitiu descrever um panorama das empresas que possuem maior retorno com o menor investimento em responsabilidade social.

\section{REFERÊNCIAS}

ASHLEY, P. A. Ética e responsabilidade social nos negócios. São Paulo: Saraiva, 2003.

BANKER, R. D.; CHARNES, A.; COOPER, W.W. Some models for estimating technical scale inefficiencies in data envelopment analysis. Managemente Science, v. 30, n.9, p. 10781092, 1984.

BELLEN, H. M. V. Indicadores de sustentabilidade: uma análise comparativa. Rio de Janeiro: FGV, 2005.

BM\&FBOVESPA. Índice de Sustentabilidade Empresarial. 2009. Disponível em: $<w w w . b m f b o v e s p a . c o m . b r / P d f / I n d i c e s / I S E . p d f>$, acesso em fevereiro de 2011.

BRUNO, G. O. A relação comercial entre empresas e fornecedores sociais: um estudo multicasos. In: FRANCISCHINI, A. S. N. (org). Responsabilidade social das empresas: a contribuição das universidades. 4. ed. São Paulo: Periópolis: Instituto Ethos, 2005. Prêmio Ethos Valor.

CARDOSO, V. I. C.; OLIVEIRA, J. D.; HOLANDA, A. P. Análise comparativa dos investimentos em responsabilidade social entre as concessionárias e não-concessionárias de 
serviços públicos: um estudo das empresas integrantes do ISE da BM\&FBovespa. In: CONGRESSO USP DE CONTROLADORIA E CONTABILIDADE, 10., 2010, São Paulo. . Anais... São Paulo: FEA/USP, 2010. CD-ROM.

CHARNES, Abraham; COOPER, William W.; RHODES, E. Measuring the efficiency of decision-marking units. European Journal of Operational Research, v. 2, p. 429-444, 1978.

DONAIRE, D. Considerações sobre a influência da variável ambiental na empresa. Revista de Administração de Empresas, São Paulo, v. 34, n. 2, p. 68-77, mar./abr. 1994.

Gestão ambiental na empresa. 2. ed. São Paulo: Atlas, 1999.

DUARTE, C. O. S.; TORRES, J. Q. R. Ética empresarial. In: FRANCISCHINI, A. S. N. (org). Responsabilidade social das empresas: a contribuição das universidades. 4. ed. São Paulo: Periópolis: Instituto Ethos, 2005. Prêmio Ethos Valor.

FERNANDEZ - CASTRO, A.; SMITH, P. Towards a general non-parametrics modelo f corporate performance. Omega - International Journal of Management Science. v.22 n.3 p. $237-249,1994$.

FRANCO, M. A. R. Planejamento ambiental para a cidade sustentável. São Paulo: Annablume; Blumenau: Ed. da FURB : FAPESP, 2000.

GIL, A. C. Métodos e técnicas de pesquisa social. 5. ed. São Paulo: Atlas, 1999.

KASSAI, S. Utilização da análise por envoltória de dados (DEA) na análise das demonstrações contábeis. 2002. 350 f. Tese (Doutorado em Ciências Contábeis) - Programa de Pós-Graduação em Controladoria e Contabilidade, Faculdade de Economia, Administração e Contabilidade, Universidade de São Paulo, São Paulo, 2002.

KINLAW, D. C. Empresa competitiva e ecológica: desempenho sustentado na era ambiental. São Paulo: Makron Books, c1997.

MACEDO, M. A. S.; ALMEIDA, K.; FONTES, P. V. S.; BARBOSA, C.; LIMA, L. C. O. Análise de desempenho contábil-financeiro no agronegócio brasileiro: aplicando DEA aos dados de agroindústrias do ano de 2006. In: CONGRESSO DA SOCIEDADE BRASILEIRA DE ECONOMIA, ADMINISTRAÇÃO E SOCIOLOGIA RURAL. 46., 2008. Anais... Acre, 2008.

MARTINS, G. A.; THEÓPHILO, C. R. Metodologia da investigação científica para ciências sociais aplicadas. São Paulo: Atlas, 2009.

MELISSA, A.; LIMONGI, B.; CEOLATTO, C. F.; PFITSCHER, E. D.; CASAGRANDE, M. D. H.; MARIAN, S. Sustentabilidade ambiental: um estudo de caso numa estação de tratamento de água e esgoto em Santa Catarina - Brasil, 2010. Disponível em: $<w w w . n e m a c . u f s c . b r / v i s u a l i z a r / c a s a n . p d f>$. Acesso em Fevereiro/2011.

PEREIRA, C. A. Avaliação de resultados e desempenhos. In: CATELLI, A. (org.). Controladoria: uma abordagem da gestão econômica - GECON. São Paulo: Atlas, 1999. 
RAUPP, F. M.; BEUREN, I. M. Metodologia da pesquisa aplicável às ciências sociais. In: BEUREN, I. M. (org). Como elaborar trabalhos monográficos em contabilidade: teoria e prática. São Paulo: Atlas, 2008.

SALAMONI, F. L.; GALLON, A. V.; MACHADO, D. D. N. Gestão ambiental e ações associadas aos custos ambientais em indústrias madeireiras de Caçador, SC. Revista ABCustos Associação Brasileira de Custo, v. 2 n. 1, p. 1-21, jan/abr 2007.

SANTOS, F. G. Responsabilidade social e demissões em massa: um olhar de relações públicas no relacionamento com o público interno. In: FRANCISCHINI, A. S. N. (org).

Responsabilidade social das empresas: a contribuição das universidades. 4. ed. São Paulo: Periópolis: Instituto Ethos, 2005. Prêmio Ethos Valor.

SANTOS, A. O.; SILVA, F. B.; SOUZA, S.; SOUZA, M. F. R. Contabilidade Ambiental: Um Estudo sobre sua Aplicabilidade em Empresas Brasileiras. Revista Contabilidade \& Finanças, São Paulo, v.16, n. 27, p. 89 - 99, set./dez. 2001.

SEIFFERT, M. E. B. Gestão ambiental: instrumentos, esferas de ação e educação ambiental. São Paulo: Atlas, 2007.

SIMAK, P. C. DEA based analysis of corporate failure. 1997. Thesis (Master of Applied Science) - Graduate Department of Mechanical and Industrial Engineering, University of Toronto. Toronto (Canada).

SIMAK, P. C. Inverse and Negative DEA and their application to credit risk evaluation. 2000. Thesis (Doctor of Philosophy) - Graduate Department of Mechanical and Industrial Engineering, University of Toronto. Toronto (Canada).

SMITH, P. Data Envelopment Analysis applied of Financial Statements. Omega International Journal of Management Science, v.18 n.2. p.131 - 138, 1990.

VASCONCELLOS, Vinícius Alburquerque; CANEN, Alberto Gabbay; LINS, Marcos Pereira Estellita. Identificando as melhores práticas operacionais através da associação benchmarking-DEA: o caso das refinarias de petróleo. Pesquisa Operacional, Rio de Janeiro, v. 26, n. 1, p. 51-67, jan/abr. 2006.

TACHIZAWA, T. Gestão ambiental e responsabilidade social corporativa: Estratégias de negócios focadas na realidade brasileira. São Paulo: Atlas, 2002. 